\title{
PENGONTROLAN AYUNAN BAYI OTOMATIS DENGAN MENDETEKSI SENSOR SUARA MENGGUNAKAN MIKROKONTROLER ARDUINO
}

\author{
Sitinur Fuji Kinasih 1), Syarli 2), Muammar ${ }^{3)}$ \\ ${ }^{1,2}$ Program Studi Teknik Informatika \\ ${ }^{3}$ Program Studi Sistem Informasi \\ UNIVERSITAS AL ASYARIAH MANDAR \\ Jl. Budi Utomo No. 2 Polewali Mandar, Sulawesi Barat
}

\begin{abstract}
ABSTRAK
Teknologi mikrokontroler telah banyak diterapkan diberbagai bidang, seperti dibidang industri, pendidikan, bisnis hingga bidang rumah tangga. Penerapan teknologi di rumah tangga akan dapat meringankan pekerjaan manusia dalam kehidupan sehari-harinya. Penelitian ini akan merancangan perangkat teknologi mikrokontroller arduino untuk membantu menggerakkan ayunan bayi. Penelitian ini menggunakan sensor suara untuk mengidentifikasikan suara tangisan bayi, dan koparator yang berfungsi untuk mengkonversi sinyal suara analog ke sinyal digital sehingga dapat diproses di mikrokontroler untuk memberikan gerakan secara otomatis. Hasil penelitian telah menunjukkan bahwa mikrokontroller telah berhasil mendeteksi suara bayi dan memberikan gerakan kepada ayunan walaupun belum sepenuhnya mampu membedakan suara bayi dengan suara lainnya.
\end{abstract}

Kata Kunci : Mikrokontroler, Arduino, Sensor Suara

\begin{abstract}
Microcontroller technology has been widely applied in various fields, such as in the fields of industry, education, business to the household sector. The application of technology in the household will be able to relieve the work of humans in their daily lives. This research will design a arduino microcontroller technology device to help move the baby's swing. This research uses a sound sensor to identify the sound of a baby's crying, and a coparator that functions to convert analog sound signals to digital signals so that they can be processed on a microcontroller to provide motion automatically. The results of the study have shown that the microcontroller has succeeded in detecting the sound of the baby and gives movement to the swing. Even though it has not been fully able to distinguish the sound of the baby from other sounds.
\end{abstract}

Keywords : Mikrokontroler, Arduino, Sound Sensor. 


\section{PENDAHULUAN}

Penerapan teknologi di masyarakat akan memberikan banyak keuntungan, karena dalam hal ini kinerja teknologi dapat meringankan pekerjaan manusia dalam kehidupan sehari-harinya.

Mikrokontroler sudah banyak diterapkan diberbagai bidang, seperti dibidang industri, bidang rumah tangga dan lain-lain. Dalam penelitian ini

penulis ingin menerapkan teknologi mikrokontroler pada ayunan bayi. Ayunan untuk bayi sendiri banyak dijumpai di pasaran, mulai dari yang sederhana yang masih menggunakan tenaga manusia untuk mengayunkan hingga yang menggunakan motor sebagai penggerak. Namun sayangnya ayunan otomatis yang terdapat dipasaran ini dapat bergerak hanya jika tombolnya diaktifkan dan akan berhenti jika tombol untuk mematikannya ditekan. Dalam hal ini, sistem berjalan kurang efisien karena jika bayi dalam kondisi tidur ayunan akan tetap bergerak mengayun selama belum dimatikan (Dianova, 2010). Hal ini menyebabkan pemborosan energi. Selain itu sistem pergerakan ayunan pun hanya dapat bergerak dengan kecepatan tertentu saja.

Untuk membuat sebuah ayunan yang bisa menyesuaikan pergerakan berdasarkan kondisi bayi diperlukan tambahan pada sistem tersebut, antara lain sistem sensor yang membaca kondisi pada bayi (Meizenta, T dkk, 2012) dan sistem kendali penggerak ayunan (motor) yang akan mengatur bagaimana ayunan tersebut bekerja (Pratyo, F., Mufida, E., 2016). Oleh karena itu, pada penelitian ini difokuskan pada perancangan sensor suara. Sensor suara pada penelitian ini dapat mengidentifikasikan suara tangisan bayi, namun dalam penempatan sensor suaranya harus dekat dengan bayi. Sensor suara yang dirancang dan dibuat pada penelitian ini merupakan sensor analog. Sensor suara terdiri dari beberapa bagian sistem mulai dari microfon yang berfungsi sebagai penangkap suara hingga koparator yang akan mengkonversi sinyal analog ke sinyal digital agar dapat diproses di mikrokontroler (Sangaji, C.S, 2016). Software Interface IDE digunakan untuk membuat pengaturan pada arduino dan relay serta perangkat eletronika lainnya (Yulias, Z., 2011).

\section{LANDASAN TEORI dan METODE}

\subsection{Arduino dan Mikrokonroller}

Arduino adalah platform prototipe elektronik yang bersifat open source yang didasarkan pada perangkat keras dan lunak yang fleksibel dan mudah digunakan sehingga dapat dengan mudah menciptakan objek atau lingkungan interaktif (Mapanji., dkk., 2015). Arduino dapat dimanfaatkan untuk mengendalikan alat eletronik lainnya, dari cara yang sederhana hingga yang kompleks seperti pengendalian lampu hingga pengontrolan robot (Muslihuddin, 2018).
Arduino adalah papan elektronik yang menggunakan mikrokontroler jenis tertentu (Bagus, H., 2017) di tunjukkan pada gambar 1.

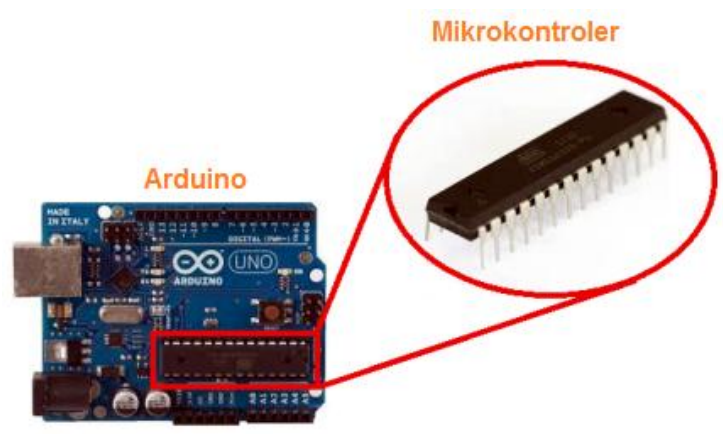

Gambar 1. Arduino dan Mikrokontroller

\subsection{Pra Rancangan Ayunan Bayi}

Desain rancangan perangkat ayunan bayi dibuat dengan sistem otomatis, pra rancangan ditunjukkan pada gamabr 2 .

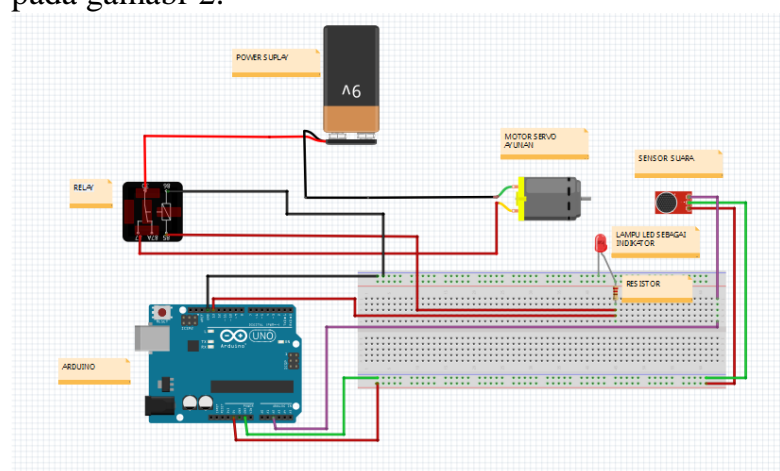

Gambar 2. Pra Rancangan Ayunan Bayi

Sistem bekerja setelah sensor suara mendeteksi gelombang bunyi dari suara tangisan bayi dan LED merah akan menyala sebagai indikator atau penanda bahwa sensor suara telah bekerja maka secara otomatis arduino akan merespon dan menyalakan relay menghubungkan ke tegangan sumber, fungsinya untuk memberikan tegangan ke dinamo atau motor servo/motor DC.

Jika tidak ada saklar pemutus, otomatis motor servo akan berputar terus-menerus (Santoso, H. 2018). Jika demikian maka ayunanannya akan mengayun tanpa terarah. Untuk memutus dan menghubungkannya kita menggunakan rangkaian flip-flop.

\subsection{Kerangka Sistem}

Sistem menggunakan alat sensor suara sehingga data inputannya berupa gelombang suara yang bersumber dari tangisan bayi dengan frekuensi tertentu. Setelah sensor suara menerima inputan dari gelombang suara, maka arduino yang telah terlebih dahulu di setting dengan sintaks yang mampu 
membaca gelombang suara atau sinyal frekuensi suara kemudian menkonversi gelombang tersebut menjadi sinyal arus listrik yang dihubungkan ke motor (mesin) penggerak yang akan menggerakkan ayunan.

Dengan demikian motor (mesin) akan bergerak otomatis mengayun sesuai dengan sinyal yang diterima. Kerangka sistem ayunan bayi otomatis pada gambar 3 meninjukkan alur kerja mulai dari input proses dan output sistem.

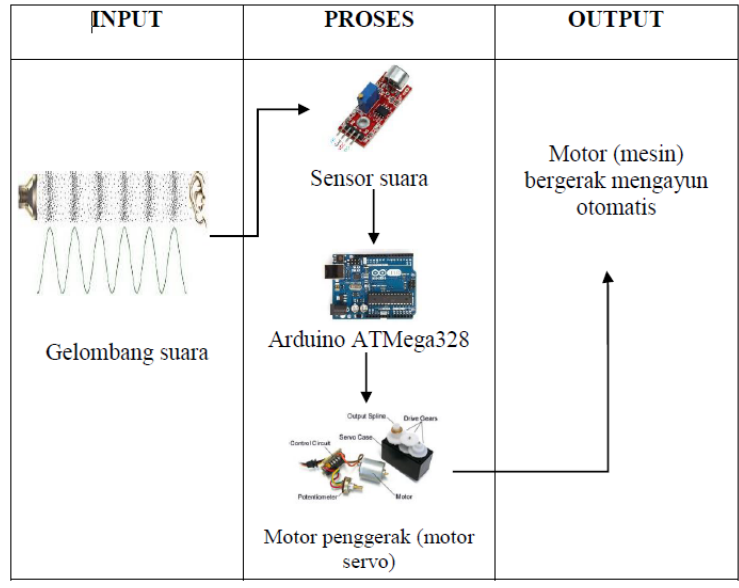

Gambar 3. Kerangka Sistem Ayunan Otomatis

\section{HASIL DAN PEMBAHASAN}

Sebuah perangkat eletronik dengan sistem otomatis yang menggunakan mikrokontroller arduino sebagai perangkat utama untuk menggerakkan ayunan bayi. Infrastruktur perangkat sistem otomatis disajikan pada gambar 4 .

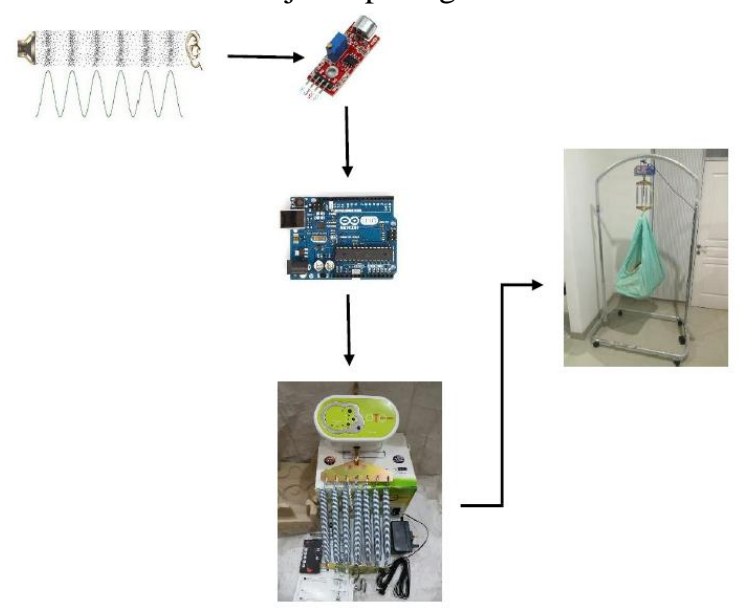

Gambar 4. Infrastruktur Teknologi Sistem Otomatis Ayunan Bayi

Perangkat eletronik pada gambar 4 berfungsi untuk menggerakkan ayunan bayi secara otomatis, perangkat ini mampu bekerja menggunakan sensor suara FC-04 yang dihubungkan ke Mikrokontroller Arduino dan relay. Hasil pengujian perangkat disajikan pada tabel 1 .
Tabel 1. Hasil Pengujian

\begin{tabular}{|c|c|c|}
\hline Action & Perangkat & Keterangan \\
\hline $\begin{array}{c}\text { Sensor suara } \\
\text { menerima } \\
\text { inputan berupa } \\
\text { suara }\end{array}$ & Mic & $\begin{array}{c}\text { Sensor } \\
\text { merespon dan } \\
\text { mengirimkan } \\
\text { sinyal analog } \\
\text { dari suara ke } \\
\text { arduino, } \\
\text { kemudian } \\
\text { arduino } \\
\text { memproses } \\
\text { sinyal tersebut } \\
\text { menjadi sinyal } \\
\text { digital }\end{array}$ \\
\hline $\begin{array}{c}\text { Sinyal analog } \\
\text { diproses } \\
\text { diarduino } \\
\text { menjadi sinyal } \\
\text { digital dan } \\
\text { dikirim ke relay }\end{array}$ & Relay & $\begin{array}{c}\text { Relay } \\
\text { merespon } \\
\text { sinyal digital } \\
\text { dari arduino } \\
\text { dalam bentuk } \\
\text { sinyal analog. } \\
\text { Relay menyala }\end{array}$ \\
\hline $\begin{array}{c}\text { Relay } \\
\text { menghubungkan } \\
\text { tegangan } \\
\text { sumber ke } \\
\text { dinamo/motor } \\
\text { servo }\end{array}$ & Motor servo & $\begin{array}{l}\text { Setelah motor } \\
\text { servo } \\
\text { mendapat } \\
\text { sumber } \\
\text { tegangan dari } \\
\text { relay, maka } \\
\text { motor bergerak } \\
\text { mengayun. }\end{array}$ \\
\hline
\end{tabular}

Perangkat arduino dan relay diatur menggunakaan software interface IDE. Berikut Gambar 5 disajikan sketch program arduino untuk pengaturan relay pada yunan bayi otomatis.

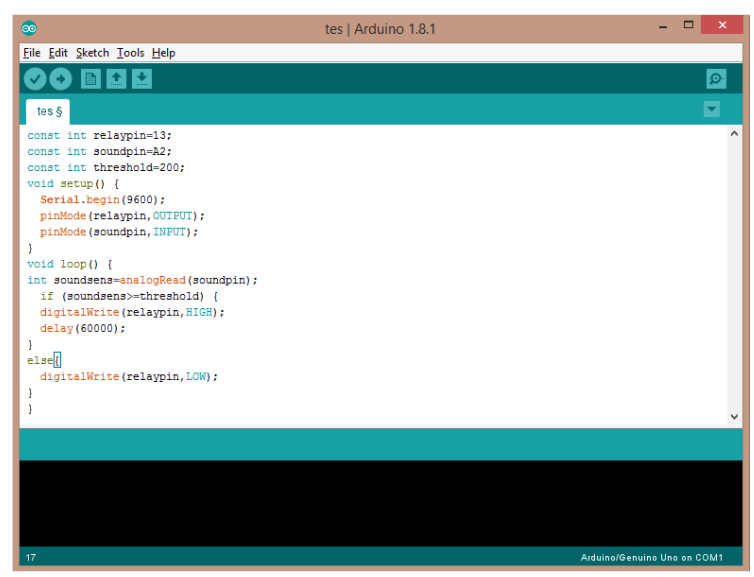

Gambar 5. Sketch Program IDE untuk pengaturan Relay

Coding pada Sketch Program diatas menjelaskan bahwa:

- const int relaypin=13; dan conts int soundpin=A2; adalah pengenalan pin 13 dan pin A2 
- pinMode(relaypin,OUTPUT); pinMode(soundpin,INPUT);

dan pengenalan sebagai input dan output. adalah

- int soundsens=analogRead(soundpin); if (soundsens $>=$ threshould) adalah, jika sensor mendapat sinyal analog maka pin 13 akan membaca HIGH atau dalam artian menyala.

- delay(60000); adalah durasi selama 1 menit

- digitalWrite(relaypin), LOW); adalah, setelah itu pin membaca LOW atau dalam artian mati.

Sensor suara menjadi parameter utama untuk menggerakkan perangkat sayangnya sensor yang dirancanga belum mampu membedakan atau mendeteksi suara bayi dengan suara lain bukan suara bayi. Sehingga sensor akan tetap bekerja meskipun sumber suaranya bukan dari suara tangisan bayi.

\section{KESIMPULAN}

Berdasarkan hasil perancangan sistem dan hasil pengujian yang telah dilakukan untuk kondisi yang mungkin terjadi pada alat pengayun bayi, maka dapat diambil beberapa kesimpulan sebagai berikut.

1. Sistem akan mulai bekerja jika sensor suara dapat dengan baik mendeteksi input .suara yang nantinya akan mengaktifkan penanda bahwa terdeteksi input suara dan mengayun secara otomatis.

2. Sensor suara akan merespon suara dengan jarak tertentu sesuai dengan apa yang telah disetting sebelumnya di sensor tersebut.

3. Ketika sensor telah mendeteksi suara tangisan bayi, maka ayunan akan bergerak/bergoyang selama 1 menit sesuai durasi yang sudah diprogram ke arduino.

Kelemahan dari prototype yaitu sensor tidak dapat membedakan suara tangisan bayi atau bukan suara tangisan.

Penelitian selanjutnya dapa melakukan ekstraksi dari ciri suara tangisan bayi untuk mendapatkan karakteristik sinyalnya. Sehingga ciri ini bisa dijadikan parameter dalam proses pengenalan suara dan sensor dapat mengidentifikasi suara tangisan bayi dengan baik, serta ayunan dapat bergerak jika hanya menerima sinyal suara dari tangisan bayi tersebut.

\section{Ucapan Terima Kasih}

Ucapan terima kasih kepada Rektor dan

Dekan serta Kepala Laboratorium riset Fakultas

Ilmu Komputer Universitas Al Asyariah Mandar.

\section{Daftar Pustaka}

Bagus, H., 2017. Arduino untuk pemula. Teknik Mikrokontroler dan Pemrograman. Modul Pembelajaran.

Dianova, O., 2010. Penggunaan Sensor Suhu dan Sensor Suara Pada Alat Pengayun Bayi Otomatis Berbasis Mikrokontroler AT89S51. Jurnal Teknik Elektro.

M. Muslihudin, Willy R., Taufiq, Andreas A., Fery Susanto., 2018 Implementasi Aplikasi Rumah Pintar Berbasis Android Dengan Arduino Microcontroller, Jurnal Keteknikan dan Sains (JUTEKS) - LPPM UNHAS Vol. 1, No.1, Juni 2018

Mapanji, A.F., Sularsa A., Sari, M.I., 2015. Prototype Ayunan Bayi Otomatis Berbasis Raspberry PI. Fakultas Ilmu Terapan Universitas Telkom.

Meizenta, T., Ningrum, E.S., Dewantara, B.S.B., 2012. Rancang Bangun Sistem Sensor untuk Aplikasi Voice Recognition Pada Ayunan Bayi Otomatis. Pliteknik Elektronika Negeri Surabaya.

Nurhadi, B.S., 2017. Sensor Suara. Program Aplikasi Berbasis Mikrokontroler. Modul Pembelajaran.

Pratyo, F., Mufida, E., 2016. Alat Ayunan Bayi Otomatis Berbasis Mikrokontroler ATMegal dengan PIR Motion Detector dan Servo. Program Studi Teknik Informatika STMIK Nusa Mandiri Jakarta.

Santoso, H. 2018, Belajar Arduino. Elektronika. Akses Internet 6 Januari 2018 pukul 15.25 WITA.

Sangaji, C.S., Harianto., Wibowo, M.C., 2016. Rancang Bangun Alat Pengayun Bayi Berbasis Mikrokontroler Menggunakan Sensor Suara, Kelembaban dan Gas Amonia. Program Studi Sistem Komputer Institut Bisnis dan Informatika Stikom Surabaya

Yulias, Z., 2011. Tutorial singkat bahasa pemrograman arduino. Akses internet 5 Januari 2018 pukul 20.15 WITA. 